This document is the accepted manuscript version of the following article:

Cai, Y., Yang, T., Mitrano, D. M., Heuberger, M., Hufenus, R., \& Nowack, B. (2020). Systematic study of microplastic fiber release from 12 different polyester textiles during washing. Environmental Science and Technology, 54(8), 4847-4855.

https://doi .org/10.1021/acs.est. 9 b07395

\title{
A systematic study of microplastic fiber release from 12 different polyester textiles during washing
}

Yaping Cai ${ }^{1}$, Tong Yang ${ }^{1}$, Denise M. Mitrano ${ }^{2}$, Manfred Heuberger ${ }^{3}$, Rudolf Hufenus ${ }^{3}$ and Bernd Nowack*1

${ }^{1}$ Technology and Society Laboratory, Empa - Swiss Federal Laboratories for Materials Science and Technology, Lerchenfeldstrasse 5, 9014 St. Gallen, Switzerland

${ }^{2}$ Process Engineering Department, Eawag- Swiss Federal Institute of Aquatic Science and Technology, Überlandstrasse 133, 8600 Dübendorf, Switzerland

${ }^{3}$ Laboratory for Advanced Fibers, Empa - Swiss Federal Laboratories for Materials Science and Technology, Lerchenfeldstrasse 5, 9014 St. Gallen, Switzerland

Contact information corresponding author:

Prof. Dr. Bernd Nowack, Lerchenfeldstrasse 5, 9014 St. Gallen, Switzerland.

Tel: +41 58765 7692, E-mail: nowack@empa.ch

Cai, Y.; Yang, T.; Mitrano, D.; Heuberger, M.; Hufenus, R.; Nowack, B. (2020). A systematic study of microplastic fiber release from 12 different polyester textiles during washing. Environ. Sci. Technol. 54: $4847-4855$.

https://dx.doi.org/10.1021/acs.est.9b07395 


\begin{abstract}
Microplastic fibers (MPF) have been found to be a major form of microplastic in freshwaters and washing of synthetic textiles has been identified as one of their main sources. The aim of this work was to use a panel of twelve different textiles of representative fiber and textile types to investigate the source(s) of the MPF released during washing. Using standardized washing tests, textile swatches tailored using five different cutting/sewing methods were washed up to 10 times. The MPF quantity and fiber length were determined using image analysis. The 12 textiles demonstrated a great variability in MPF release, ranging from 210 to 72 '000 MPF/g textile per wash. The median MPF length ranged from $165 \mu \mathrm{m}$ to $841 \mu \mathrm{m}$. The number of released MPF was influenced by the cutting method that scissor-cut samples released 3 - 21 times higher numbers of MPF the laser-cut samples. The textiles with mechanically processed surfaces (i.e. fleece) released significantly more (p-value $<0.001)$ than the textiles with unprocessed surfaces. For all textiles, the MPF release decreased with repeated wash cycles and a small continuous fiber release was observed after 5-6 washings, accompanied by a slight increase in fiber length. The decrease in the number of MPF released is likely caused by depletion of the production-inherited MPFs trapped within the threads or the textile structure. The comparison of MPF release from laser-cut samples, which had sealed edges, and the other cutting methods allowed us to separate the contributions of the edge- and surface-sourced fibers from the textiles to the total release. On average, $84 \%$ (range 49-95\%) of the MPF release originated from the edges, highlighting the importance of the edge-to-surface ratio when comparing different release studies. The large contribution of the edges to the total release offers options for technical solutions which have the possibility to control MPF formation throughout the textile manufacturing chain by using cutting methods which minimize MPF formation.
\end{abstract}

\title{
Graphical abstract
}

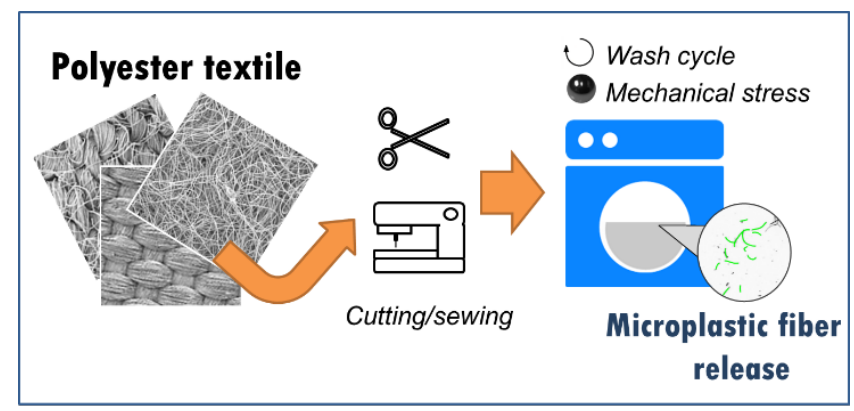




\section{Introduction}

The ubiquitous presence of microplastics in the environment ${ }^{1-6}$ as well as in biota ${ }^{7,8}$ has been reported by hundreds of studies. A mixture of fibers, beads, and fragments were usually found in environmental samples, where microplastic fibers (MPF) were reported to account for a large proportion of all microplastics ${ }^{9-11}$. A modeling study has shown that fibers released from textiles are one of the most important sources of microplastics in freshwaters ${ }^{12}$. One pathway is likely from synthetic clothing where domestic washing may release a high number of fibers ${ }^{13}, 14$. Although the removal efficiency of microplastics in wastewater treatment plants can reach $98 \%$ or higher ${ }^{15,16}$, the few percent of MPF which are not captured can make a contribution of about $20 \%$ to the microplastic release to freshwaters ${ }^{12}$. Alternatively, MPF captured during water treatment can enter the terrestrial environment when sewage sludge is applied on soil ${ }^{17-20}$.

Several studies have investigated the general release of MPF from textiles during washing, addressing a few factors in isolation that were hypothesized to control the release $\mathrm{e}^{13,21-32}$. The MPF release was mostly found to decrease with increasing number of wash cycles ${ }^{21,27-32}$, sometimes reaching a plateau between the $4^{\text {th }}$ and $5^{\text {th }}$ wash $^{30,31}$. However, a relative stable release over time was also observed in one study, which proposed that MPF may have been formed during textile manufacturing process prior to washing $^{24}$. The addition of liquid or powder detergents was reported to either increase ${ }^{22,24,27}$ or have no impact $^{28,32}$ the MPF release compared to pure water, while textile softeners were found to significantly reduce the MPF release ${ }^{22}$. A recent study revealed that a higher water volume can elevate the release of MPF during washing because of the increasing hydrodynamic pressure on fibers ${ }^{32}$. In addition, other factors including temperature, duration of the wash cycle and mechanical stress (number of steel balls added to the container) were investigated, but there was no significant influence of these factors on the MPF release $\mathrm{e}^{22,24,32}$.

The textile samples tested in previous studies were either garments purchased on the market ${ }^{14,23,26,27,29}$ or consisted of only a limited types of textile samples ${ }^{21,22,24,25}$. Although efforts have been made to compare MPF release between different washing system ${ }^{33}$, considering the variability of experimental protocols adopted by the different studies, it is still difficult to comprehensively compare the results on MPF release from textiles with different properties (e.g. surface treatment, textile structure and yarn type) and to gain an integrated insight on how those properties influence the MPF release through the washing process. Furthermore, the cutting method has been identified as being one of the most critical factors affecting the number of MPF released from textiles during washing ${ }^{25}$. The most commonly used cutting approach in industry is mechanical cutting where knives are vertically guided to cut multiple layers of textiles ${ }^{34}$. Besides, thermal cutting is also applied during textile tailoring ${ }^{34}$. Then cut edges are often sewn with stiches in the later step. Similar to the industry, many studies adopted either mechanically cut swatches with sewn edges ${ }^{31}$ or thermally cut swatches ${ }^{21,32}$ to reduce MPF shedding 
from edges. However, it is still unclear whether those procedures can really prevent MPF release from the edge and how the cutting/sewing method affects MPF release.

Therefore, the aim of our study was to systematically investigate the influence of textile properties and tailoring methods on the MPF release during washing. In particular, we place special emphasis on studying the influence of industrially used cutting/edge sewing methods. We suspect that: 1) MPFs are already present in the textile before washing and are only released but not generated through the washing procedure; 2) MPF release from textiles during washing will be affected by textile properties such as surface treatment, textile structure and/or yarn type); 3) higher mechanical stress will lead to increased MPF release; 4) textiles with tailored edges will release fewer MPFs than the textiles with scissor-cut edges without any treatment. The results from this work will not only form a basis for the understanding of the mechanisms which influence MPF release from textiles during washing, but also provide evidence to help the industry to develop better mitigation strategies.

\section{Materials and methods}

\subsection{Textiles}

A set of 12 commercially available polyester textiles were obtained directly from different manufacturers (Table 1). Seven of the textiles were made of filament yarns and five of spun staple fiber yarns. The suffix "S" or "F" was used to distinguish textiles made from spun yarns (staple-length fibers) or filament yarns (endless fibers), respectively. Six woven and six knitted textiles were used. The production of some types of textiles can include a mechanical surface treatment, where the surface fibers are cut to create a fuzzy or soft texture of the final product ${ }^{34,35}$. For the fleece, there is a shearing process where the surface fibers are cut by a blade. For textiles with brushed surface, the break of surface fibers is usually carried out by a metal brush in the brushing process. In our study, a fleece textile and a plain textile with brushed surface was investigated and they were referred as textiles with processed surface. The suffix "B" was given to the plain textile with a brushed surface. A microfiber cloth containing fibers with a much smaller diameter than all the other textiles was also included. All samples were dark-colored and ranged in density from 75 to $294 \mathrm{~g} / \mathrm{m}^{2}$ (determined by weighing three pieces of $36 \mathrm{~cm}^{2}$ samples). FTIR analysis (Varian 640-IR) confirmed the chemical composition (polyester) of all textile samples.

Scanning electron microscopy (SEM) (Hitachi S6200, 2.0kV, x40) was used to characterize the textile structure and fiber diameter (Table 1, Table S1). Before observation under the SEM, a layer of $7 \mathrm{~nm}$ $\mathrm{Au} / \mathrm{Pd}$ was sputtered on the samples' surface by a high vacuum sputter coater (LEICA EM ACE600) to enhance the contrast. To determine the fiber diameter, ten fibers from the textile were randomly measured on the SEM image. 
Table 1. Characterization of textile physical properties.

\begin{tabular}{|c|c|c|c|c|c|c|}
\hline Surface & Structure & Type & Yarn & Color & Density $\left[\mathrm{g} / \mathrm{m}^{2}\right]$ & Fiber diameter $[\mu \mathrm{m}]$ \\
\hline \multirow{9}{*}{ Unprocessed } & \multirow{5}{*}{ Knit } & Interlock & Spun & Black & $209 \pm 1$ & $12.2 \pm 0.8$ \\
\hline & & Jersey & Spun & Black & $226 \pm 1$ & $12.8 \pm 0.8$ \\
\hline & & Rib & Spun & Black & $294 \pm 2$ & $12.7 \pm 1.1$ \\
\hline & & Rib & Filament & Black & $199 \pm 1$ & $15.9 \pm 2.2$ \\
\hline & & Terry & Spun & Black & $208 \pm 2$ & $13.0 \pm 1.3$ \\
\hline & \multirow{4}{*}{ Woven } & Plain & Spun & Black & $100 \pm 0$ & $12.7 \pm 0.5 / 13.4 \pm 0.9^{*}$ \\
\hline & & Plain & Filament & Black & $149 \pm 1$ & $7.5 \pm 0.6 / 7.9 \pm 0.5^{*}$ \\
\hline & & Twill & Filament & Black & $154 \pm 1$ & $12.4 \pm 1.8 / 19.9 \pm 1.7^{*}$ \\
\hline & & Satin & Filament & Black & $75 \pm 0$ & $13.0 \pm 0.7 / 16.4 \pm 1.7^{*}$ \\
\hline \multirow{3}{*}{ Processed } & Knit & Fleece & Filament & Black & $185 \pm 1$ & \multirow{3}{*}{$\begin{array}{c}11.7 \pm 1.3 \\
9.0 \pm 1.2 / 10.1 \pm 1.5^{*} \\
19.9 \times 8.9 / 7.7 \times 2.2^{* *} \\
\text { (microfiber) }\end{array}$} \\
\hline & Woven & Plain brushed & Filament & Black & $131 \pm 0$ & \\
\hline & Woven & - & Filament & Grey & $191 \pm 3$ & \\
\hline
\end{tabular}

*The diameters of the weft and the warp yarns of the woven textiles

$* *$ The width and length of the weft yarn $(19.9 \pm 1.1 \times 8.9 \pm 1.2 \mu \mathrm{m})$ and the warp yarn $(7.7 \pm 0.9 \times 2.2 \pm 0.5$ $\mu \mathrm{m})$ with a rectangular cross section for the microfiber sample

\subsection{Sample preparation}

Textiles were cut into small pieces with sizes depending on the requirement of the experiments (Figure 1). For the first three sets of experiments, the swatches were cut either with textile scissors or a laser cutter (tt-1300, Times technology) into pieces of $4 \times 10 \mathrm{~cm}$ according to the ISO standard 105-C06 $6^{36}$. The weight of these samples ranged between 0.29 and $1.30 \mathrm{~g}$. To discriminate the influence of the cutting/sewing methods, an additional set of textile swatches were cut to a larger size of $10 \times 10 \mathrm{~cm}$ to have enough area available to sew the edges. Three additional types of cutting/sewing methods commonly used in industry were investigated: model cutting (MC) (SAMCO type SB 25 A), overlock sewing (OS) and double-folded sewing (DS). An overlock sewing machine (BERNINA 2000D) was used to sew the edges with overlock stiches (width: $5 \mathrm{~mm}$; length: $2.5 \mathrm{~mm}$; density: 10 stiches per inch), which is one of the most commonly used stiches to tailor the edges in garment manufacturing. For the double-sewn samples, the edges were folded twice and then sewn with simple stiches (length: $1.5 \mathrm{~mm}$; density: 17 stiches per inch) as described in our previous study ${ }^{24}$. Both overlock- and double-sewn samples were originally scissor-cut, and white cotton threads were used to sew the samples so that it would not interfere with our MPF analysis later in the study. The contribution of the sewing thread to the total weight of the finished sample was between $3 \%$ and $6 \%$. The size of a finished double-sewn swatch was approximately $5 \times 5 \mathrm{~cm}$ with an average weight of 1.47 and $2.29 \mathrm{~g}$ per piece for Plain $\mathrm{F}$ and Interlock S, respectively. Examples of the finished samples can be found in Figure S1. 


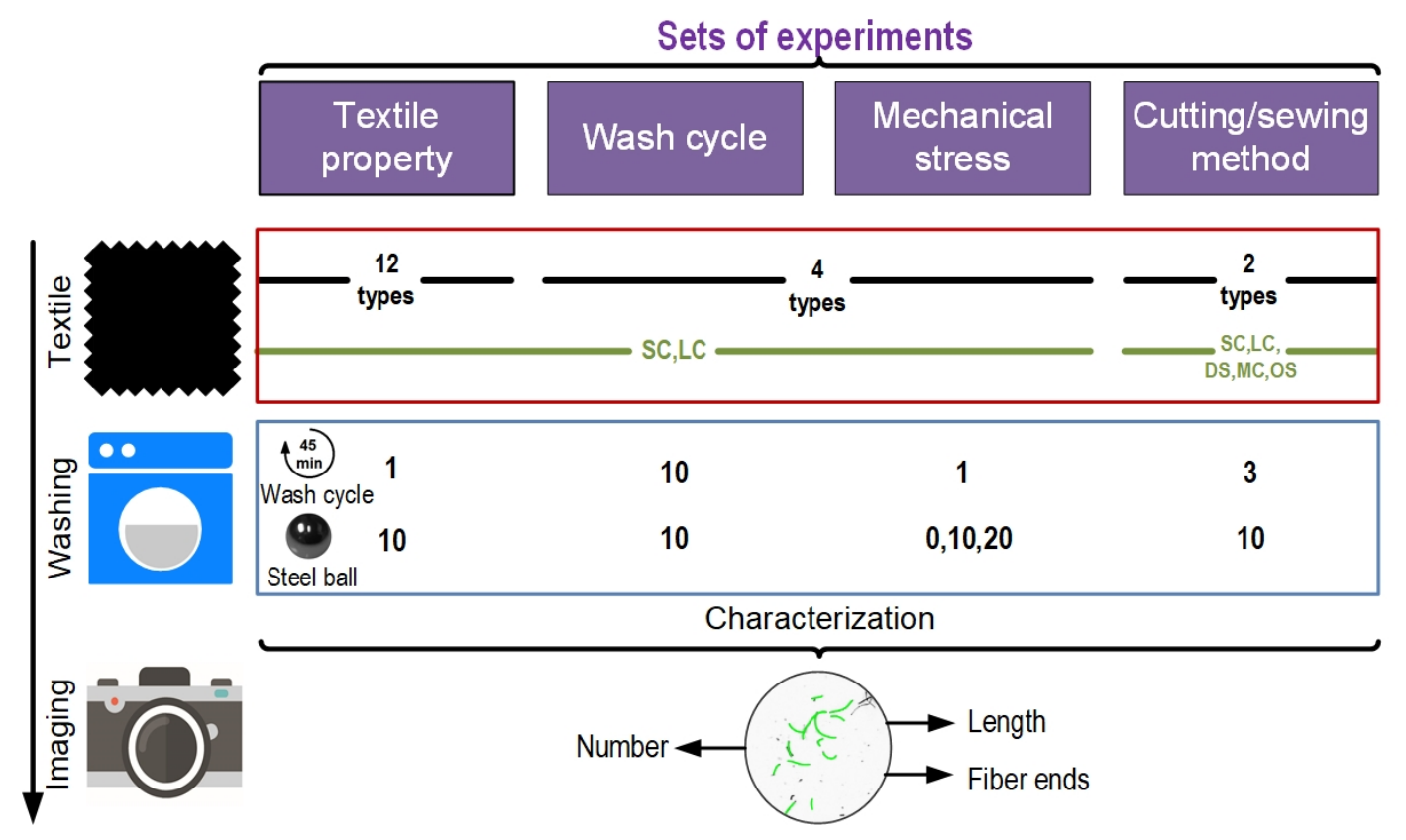

Figure 1. Flow chart of the study. 12 types: 12 types of textiles as shown in Table 1; 4 types: Fleece, Interlock S, Plain F, Plain S; 2 types: Plain F and Interlock S. SC: scissor cutting; LC: laser cutting; DS: double-folded sewing; MC: model cutting; OS: overlock sewing.

\subsection{Washing experiments}

Domestic washing was simulated by a Gyrowash lab washing machine (James Heal, GyroWash Model 1615). Before each wash cycle, the steel vessels were rinsed with deionized water $\mathrm{H}_{2} \mathrm{O}$ three times and a five minute rinse cycle with linear alkylbenzene sulfonic acid (LAS) solution $(0.75 \mathrm{~g} / \mathrm{L}, \mathrm{pH} 9.2 \pm 1)$ was performed. LAS solution was used to simply mimic the liquid laundry detergent commonly containing a more complex composition used in households, as was done in our previous study ${ }^{24}$. Two of the eight steel vessels were used as blanks containing only LAS solution in each experimental round and the blank vessels were always randomly chosen for the next round of experiments. No prewash step was performed on the textile samples. All experiments were performed in triplicates. A schematic of the work flow is shown in Figure 1. The washing experiments were conducted following a standardized wash procedure from ISO $(105-\mathrm{C} 06,1994)$ with a slight modification of the washing solution (Table S3) and no adjacent textile was used. One piece of textile was added to a steel vessel (500 $\mathrm{ml})$ with 150 $\mathrm{ml}$ LAS solution together with ten steel balls (diameter of $6 \mathrm{~mm}$ ). Each wash cycle lasted for $45 \mathrm{~min}$ at a temperature of $40{ }^{\circ} \mathrm{C}$. This standardized washing condition was applied once to all 12 textiles in the experiment which investigated the influence of textile properties on MPF release. To determine the influence of repeated wash cycles on MPF release, four representative textile variants (Fleece, Interlock S, Plain F, Plain S) with scissor-cut and laser-cut edges were washed for ten rounds following the washing condition as described above. The wash liquid from $1^{\text {st }}, 2^{\text {nd }}, 3^{\text {rd }}, 5^{\text {th }}, 8^{\text {th }}$ and $10^{\text {th }}$ round was filtered and analyzed. The influence of mechanical stress on the MPF release was investigated by adding 
different number of steel balls $(0,10$ and 20$)$ for the four selected samples (Fleece, Interlock S, Plain F, Plain S). To study how the edge treatment influenced the MPF release, samples of two selected textiles (Plain F and Interlock S) were prepared with five different cutting/sewing methods as described in the previous section. The experiments followed the standardized conditions and three wash cycles were performed for each treatment.

\subsection{Water collection and filtration}

After each wash cycle the textile sample was taken out of the vessel with tweezers and allowed to drip for 15 seconds to drain excess liquid. The washing liquid remaining in the vessel was continuously stirred to keep the suspension homogenous. Then the liquid was transferred by a $10 \mathrm{ml}$ pipet to a filtration system consisting of a filtration unit and a vacuum pump. The wash water was filtered through a cellulose nitrate membrane (GE Whatman diameter $4.7 \mathrm{~cm}$, pore size $0.45 \mu \mathrm{m}$ ). To avoid too many overlapping fibers on the filters, the volume of the filtered solution was adjusted to be between 1 and 50 $\mathrm{mL}$ depending on the MPF concentration, aiming for 100 to 200 MPFs per filter. All filters were dried in separate petri dishes (VWR, diameter $90 \mathrm{~mm}$, height $16 \mathrm{~mm}$ ) covered with corresponding caps at room temperature overnight.

\subsection{Filter imaging and analysis}

The filters were imaged by a single-lens reflex camera (Nikon D850) with a macro lens (Nikon 105 $\mathrm{mm} / 2.8$ ) together with a calibration slide for microscope with a smallest scale of $100 \mu \mathrm{m}$ (VWR Catalog number: 630-1123). The images ( 8256 x 5504 pixels) were edited in the software Adobe Lightroom CC (version: 2015.14) to enhance the contrast. All images were analyzed with the software FiberApp (version: 1.51$)^{37}$ for MPF number and length. The semi-automatic software allowed manual selection of the starting and the end points of each fiber and automatically recorded the fiber number and calculated the fiber length. In total, the individual lengths of 52,800 MPF were recorded from 530 filters with a detection limit of 7-8 pixels, corresponding to about $90 \mu \mathrm{m}$ in length. Examples of filter images can be found in Figure S2 and S3. Additionally, to determine the mechanism of fiber breakage, fibers released from Interlock $\mathrm{S}$ during the $1^{\text {st }}$ and $10^{\text {th }}$ washing cycle on the filter were sampled by adhesive tape and nine fibers were randomly selected to image the fiber ends with SEM (Hitachi S6200, 2.0kV, $\mathrm{x} 1.80$ ). The experimental procedure was assessed in terms of level of contamination and reliability of a standardized workflow, which can be found in the supplementary information.

The mass of released MPF from knit textiles was calculated by multiplying the density of polyester (1.38 $\left.\mathrm{g} / \mathrm{cm}^{3}\right)^{38}$ by the measured length and the known diameter of the fibers (Table 1). For woven textiles, the 
mass cannot be calculated because there are two types of yarns with different diameters which we could not separate with the chosen image analysis method.

\subsection{Statistics}

For the experiment investigating textile properties, the influence of three factors including the surface treatment (unprocessed, processed), the textile structure (knit, woven), and the yarn type (spun, filament) on the number and length of MPF released from scissor- and laser-cut textiles was determined by a linear mixed model (package "ImerTest") in R (version 3.4.3.) respectively. The three factors and the textile types (Interlock, Plain and etc.) were considered as fixed and random effects, respectively. For the other experiments, a one-way ANOVA test in IBM SPSS software (version 25) was used to determine the impact of different treatments on the number of MPF released in the following groups: 1) mechanical stress: experiments with different steel balls; 2) cutting/sewing methods: five different ways of cutting/sewing technique. A non-parametric Kruskal-Wallis (K-W) one-way ANOVA test in IBM SPSS software (version 25) was applied to compare the length distribution of the mentioned groups. The pvalue of any statistical test below 0.05 was considered to indicate statistical significance.

\section{Results}

\subsection{MPF release from 12 polyester textiles}

The number of released MPF per wash demonstrated a large variety ranging from $210 \mathrm{MPF} / \mathrm{g}$ for lasercut Twill F to 72,000 MPF/g for scissor-cut Microfiber (Figure 2A, Table S4). The majority of the MPF exhibited a length between 100 to $1000 \mu \mathrm{m}$ (Figure 2B, Table S5). The shortest MPFs were released from laser-cut Microfiber (median: $165 \mu \mathrm{m}$ ), while the longest MPF were found from scissor-cut Terry S (median: $841 \mu \mathrm{m})$.

Furthermore, the cutting method and the surface treatment of the textile were found to have significant impact on the MPF release. The scissor-cut samples released 3 - 21 times higher numbers of MPF than the laser-cut textiles (Figure 2A). The length distribution was displayed in a notched box plots, where there is a strong evidence ( $95 \%$ confidence) of different medians if two boxes' notches do not overlap ${ }^{39}$. For most of the samples, the MPF shed from the scissor-cut samples exhibited longer length (Figure 2B). The textiles with mechanically processed surfaces released significantly more MPF (p-value < $0.001)$ than textiles with unprocessed surfaces for both scissor-cut and laser-cut samples. On the other hand, the linear mix model shows that the textile structure and the yarn type were found to have no significant influence on the number of MPF released. The MPF length seemed to be influenced by textile structure and surface treatment depending on the cutting methods. The scissor-cut woven textile and the laser-cut textile with processed surface shed significantly shorter MPFs than the knit textile (p-value = $0.0297)$ and the textile with unprocessed surface (p-value $<0.001)$ respectively. 


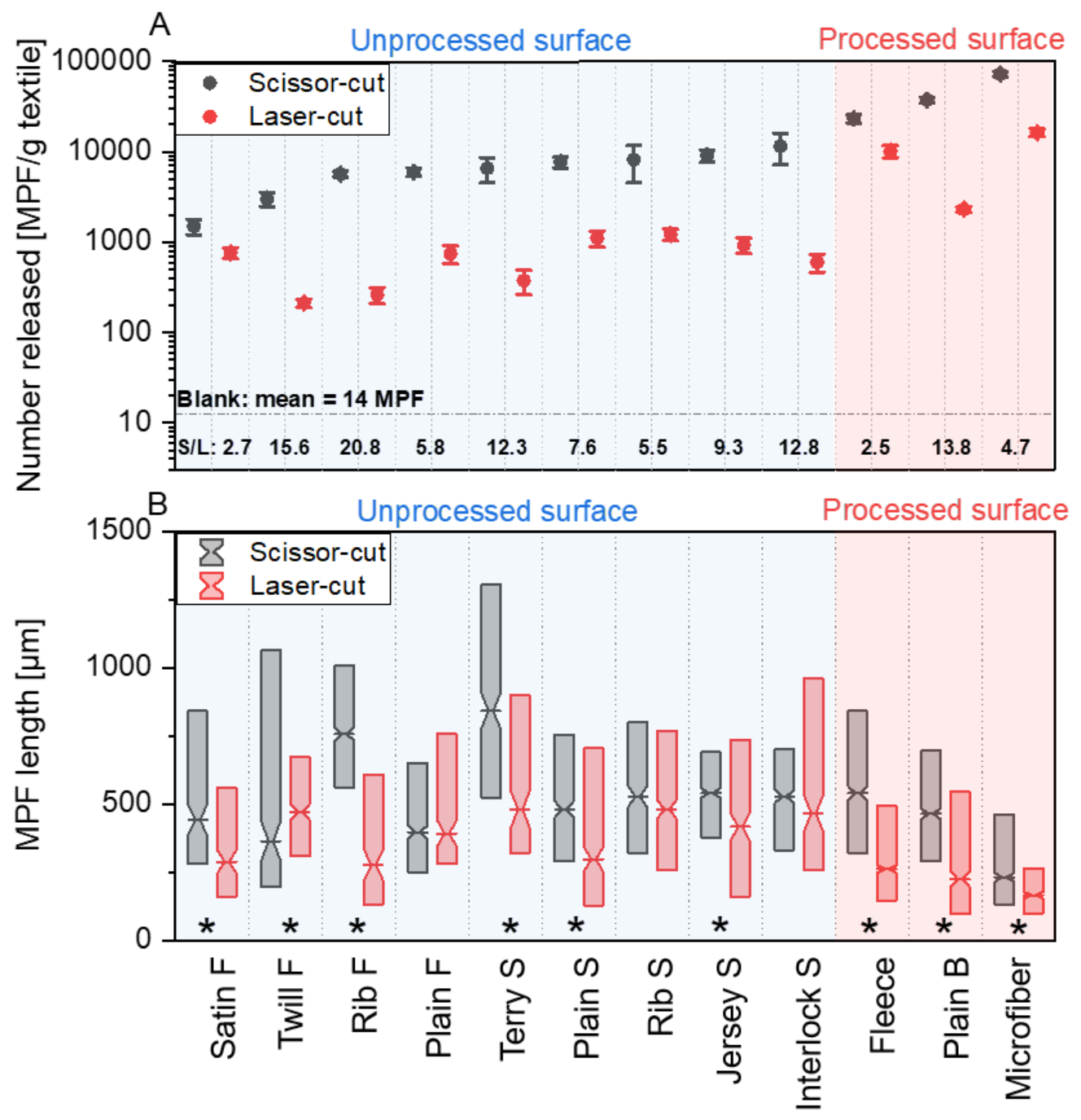

Figure 2. A) Number of MPF released from 12 polyester textiles during the $1^{\text {st }}$ wash cycle in number of MPF per gram of textile. The mean values are represented by the black dots (scissor-cut) and red dots (laser-cut). Error bars show the standard deviation for three experimental replicates. The mean of the blanks for this set of experiments is displayed as a horizontal line. S/L stands for the scissor to laser ratio, which was calculated number of released MPF from SC sample divided by LC sample; B) Length distribution of MPF released during the $1^{\text {st }}$ wash cycle. The values presented here are a summation of triplicate experiments. The number of MPF plotted per box was between 182 and 1498, with an average of 560. The boxes represent $25^{\text {th }}$ and $75^{\text {th }}$ percentiles with the median indicated by a line. The notches represent $95 \%$ confidence interval for the median. Whiskers and outliers are not shown on the graph. The complete datasets can be found in Figure S5. Asterisks are given to those where the median length was significantly different between laser-cut and scissors-cut samples

\subsection{MPF release during repeated wash cycles}

To investigate the influence of repeated wash cycles on MPF release, four textiles were washed for ten wash cycles and the wash liquid from selected rounds were filtered and analyzed. A decrease in the number of MPF released in the first three wash cycles was observed for all the samples (Figure 3, Table S6 and S7). Depending on the type of textiles, six to 120 times higher numbers of MPF were released in the $1^{\text {st }}$ wash cycle than the $10^{\text {th }}$ wash cycle. After 3 to 5 wash cycles, the number of released MPF either stabilized at a lower level or slightly increased. The number of MPF released after the $10^{\text {th }}$ wash 
cycle was still above the blank (4 MPF per filter) with an average between 10 and $1200 \mathrm{MPF} / \mathrm{g}$. In terms of length, most of the samples released significantly shorter MPFs in the $1^{\text {st }}$ wash cycle compared to the $10^{\text {th }}$ cycle (Figure 4, Table S8), especially for Fleece. To determine the mechanism of fiber breakage, MPFs were randomly selected to characterize the morphology of fiber ends by SEM and the images suggest that the most MPFs released from the $1^{\text {st }}$ (Figure 5A) and $10^{\text {th }}$ (Figure 5B) wash cycles had ends similar to those caused by the scissor cutting (Figure 5D). In addition, a comparison between the MPFs shed from scissor- and laser-cut samples (Figure 5A and 5C) shows that both sample shed some MPFs with distorted ends, but MPFs possessing molten ends were exclusively found for laser-cut samples.
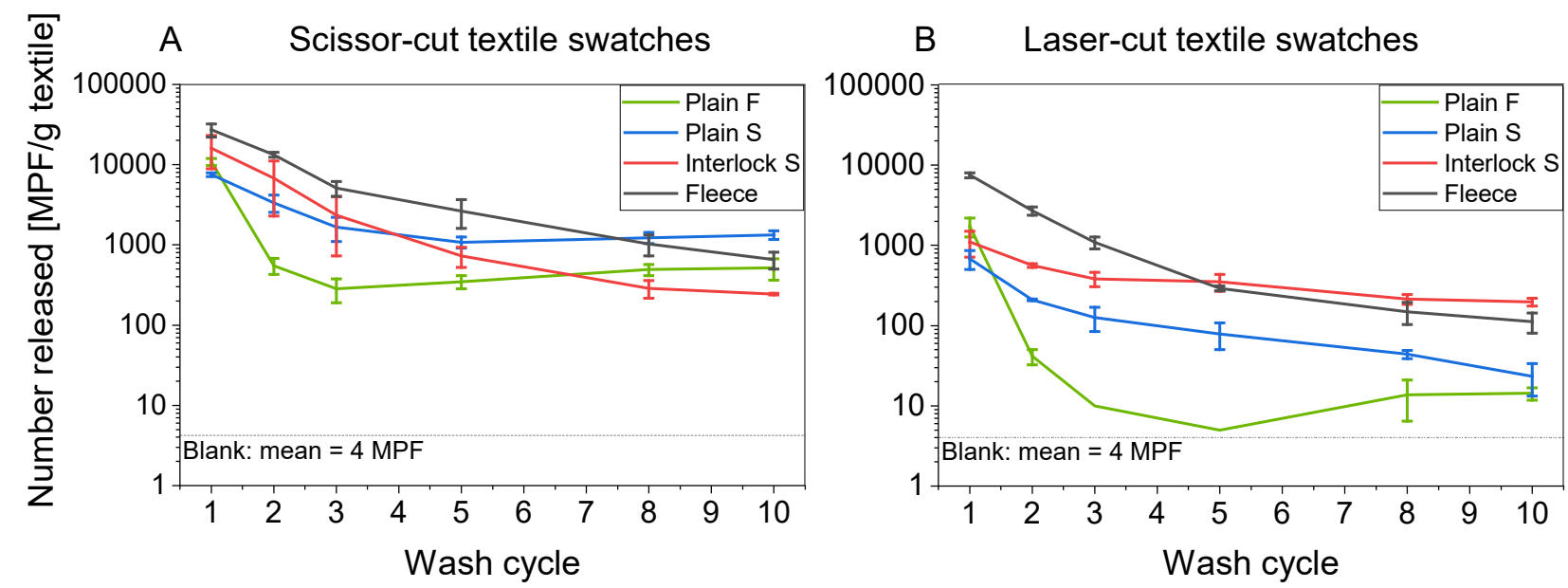

Figure 3. Number of MPF released per cycle, as a function of the number of wash cycles for Plain F, Plain S, Interlock S and Fleece. A) and B) are for scissor-cut and laser-cut samples, respectively. All values are presented in MPF per gram of textile. Error bars show the standard deviation for three experimental replicates. The mean of blanks ( $n=4 \mathrm{MPFs})$ for this set of experiments is displayed as a horizontal line. 

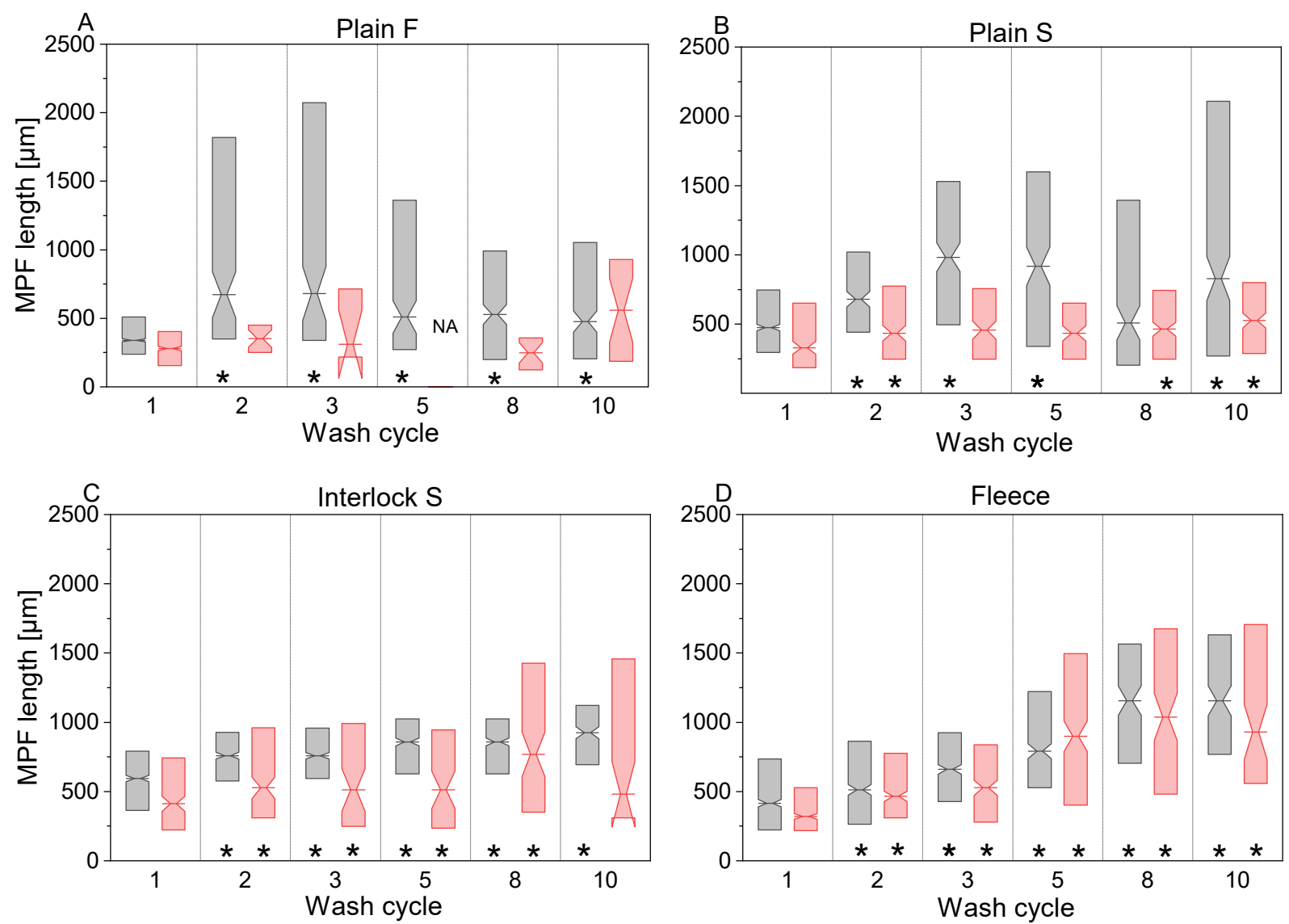

Figure 4. Length distribution of MPF released during the $1^{\text {st }}, 2^{\text {nd }}, 3^{\text {rd }}, 5^{\text {th }}, 8^{\text {th }}$ and $10^{\text {th }}$ wash cycle. NA: less than five MPFs. The values here were a summation of triplicate experiments. The number of MPF plotted per box was between 10 and 1277 with an average of 318 . The boxes represent $25^{\text {th }}$ and $75^{\text {th }}$ percentiles with the median indicated by a line. Whiskers and outliers are not shown on the graph. The complete datasets can be found in Figure S6. Asterisks are given to those samples where the median length was significantly different from the $1^{\text {st }}$ release. 

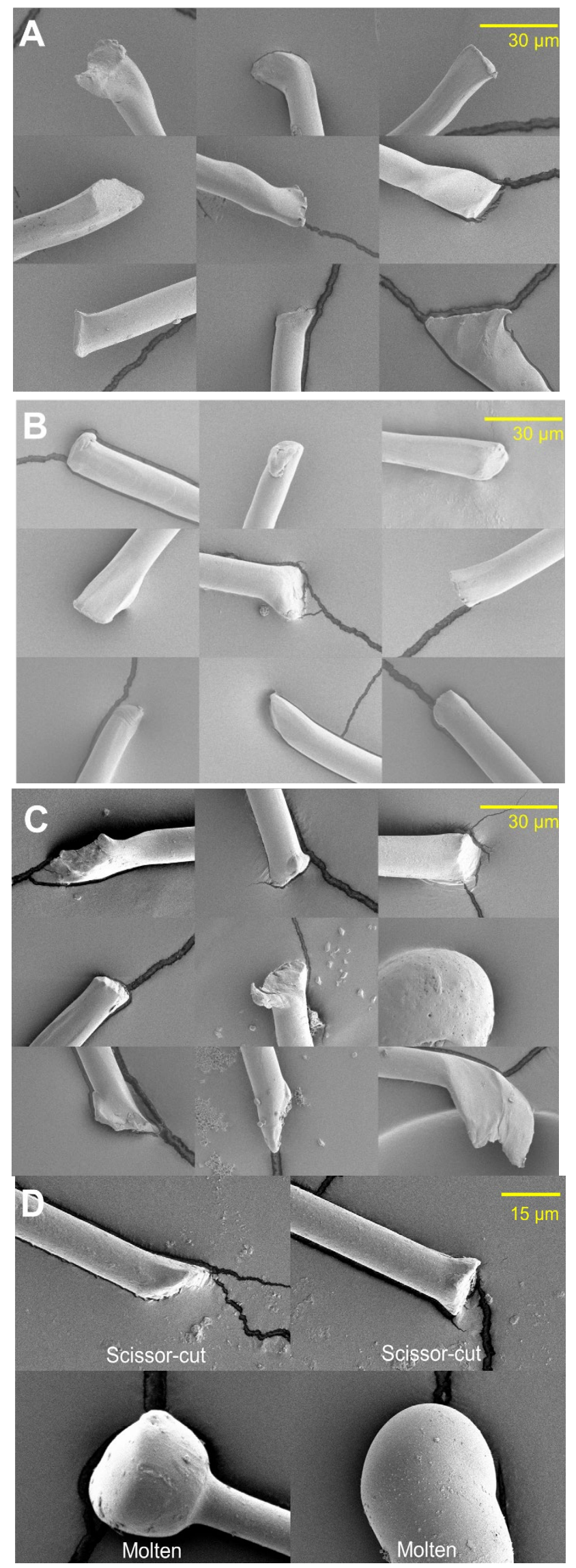

Figure 5: Characterization of MPFs released from Interlock S A: scissor-cut, $1^{\text {st }}$ wash cycle; B: scissorcut, $10^{\text {th }}$ wash cycle; C: laser-cut, $1^{\text {st }}$ wash cycle; D: Examples of scissor-cut and molten fiber ends. SEM images were taken under $2 \mathrm{kV}$ and the magnification was $1.80 \mathrm{k}$. 
To calculate the cumulative release of MPF during the ten wash cycles, the number of MPF released from $1^{\text {st }}$ to $10^{\text {th }}$ wash cycles was summed up. An interpolation was made for the cycles were no analysis was performed $\left(4^{\text {th }}, 6^{\text {th }}, 7^{\text {th }}\right.$ and $9^{\text {th }}$ wash cycles). We assumed that the number of released MPF in the wash cycles which were not analyzed was the mean number of its neighboring cycles. For instance, to estimate the release during $4^{\text {th }}$ wash cycle, we averaged the number of MPF released from $3^{\text {rd }}$ and $5^{\text {th }}$ wash cycles. The resulting cumulative release is shown in Table S9. The release during the first wash cycle accounted for 30\% (Plain S) to $90 \%$ (Plain F) of the cumulative release.

\subsection{MPF release with different mechanical stress and cutting/sewing methods}

The number of steel balls added $(0,10$ and 20) did not show a statistically significant impact on the number of MPF released for the majority of tested samples including Plain F, Interlock S and Fleece (Figure S7, Table S10). On the other hand, a similar MPF length distribution was found for most of the textiles regardless of the level of mechanical stress during the experiments.

Five different cutting and sewing methods were tested to examine their influence on MPF release. Only laser cutting significantly reduced the amount of the MPF release from textiles during washing (Figure 6, Table S11). Laser-cut Interlock S released a cumulative number of 1'300 MPF/g in the first three washes which was about 7 to 12 times lower than for the other cutting/sewing methods. Similar results were found for Plain F, where the laser-cut sample shed fewer MPFs (370 MPF/g) than the other treatments $\left(3760-7^{\prime} 400 \mathrm{MPF} / \mathrm{g}\right)$. No significant difference was found for the number of MPF released between the other four types of cutting/sewing methods (scissor-cut, model-cut, double-sewn, overlocksewn) for Interlock S. However, for Plain F, the overlock-sewn sample released 1.5 to 20 times more MPF (7’ $400 \mathrm{MPF} / \mathrm{g})$ than the other cutting/sewing methods. In addition, all treatments decreased the number of MPF released through multiple wash cycles (Figure S9 and S10).

The length of MPF released from the textile with different cutting/sewing methods exhibited a larger variability for Plain F than for Interlock S. Scissor-cut Plain F released approximately two times longer MPF (median: $434 \mu \mathrm{m}$ ) than the double-sewn samples (median: $204 \mu \mathrm{m}$ ) during the $1^{\text {st }}$ wash cycle, while the Interlock S released MPFs with length ranged from 363 (double-sewn) to $528 \mu \mathrm{m}$ (model-cut). For both textiles, the shortest MPF were found for double-sewn samples. 

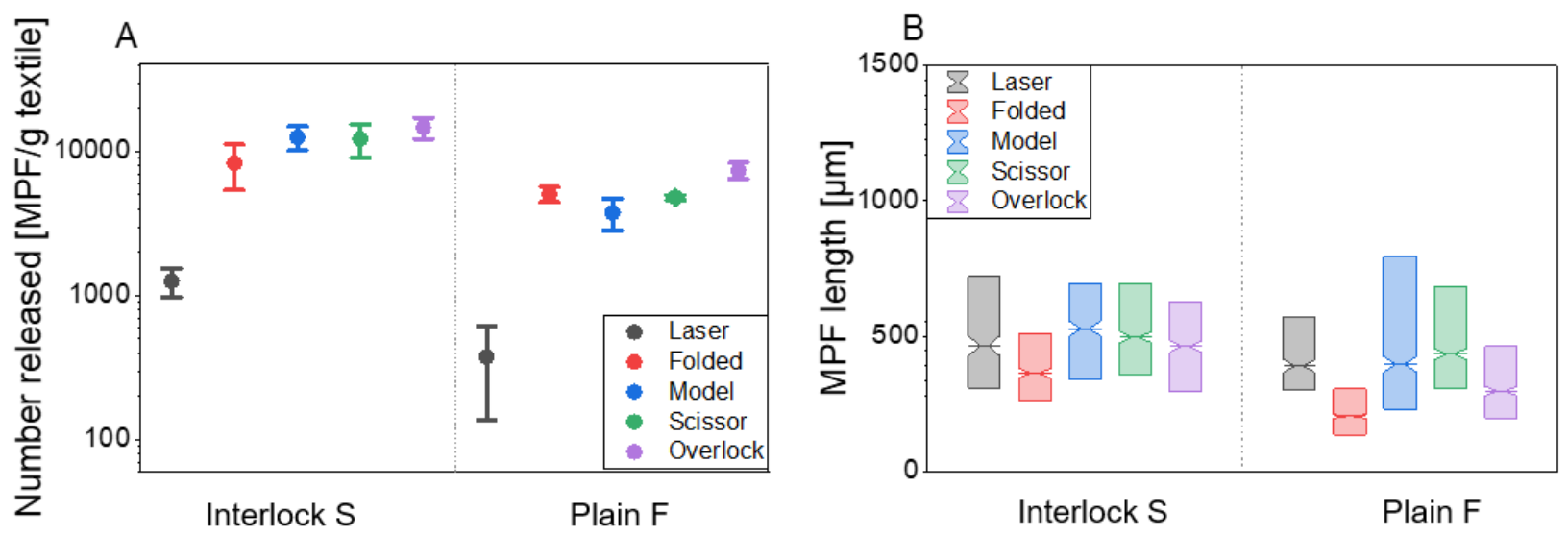

Figure 6. A) Influence of the cutting/sewing method on the number of MPFs released from two textiles during the $1^{\text {st }}$ wash cycle. The mean values are represented by black (laser-cut), red (double-sewn), blue (model-cut), green (scissor-cut) and purple (overlock-sewn) symbols. Error bars indicate standard deviation for three experimental replicates; B) Length distribution of MPF released during the $1^{\text {st }}$ wash cycle. The boxes represent $25^{\text {th }}$ and $75^{\text {th }}$ percentiles with the median indicated by a line. Whiskers and outliers are not shown on the graph. The complete datasets can be found in Figure S8.

\section{Discussion}

Our work explored the hypothesis that a significant fraction of MPF released during washing of textiles were already present in the textile during the manufacturing process and not produced during the number of wash cycles investigated here. We found that the number of MPF released was greatly influenced by the number of wash cycles, with fewer MPF observed in the wash water after the first cycle, as has been observed in other studies ${ }^{21,27-32}$. This strongly indicates that MPF were present in textile products before washing and that the act of washing released the MPF which were on/in the textile. The morphology of the fiber ends can inform us about the processes responsible for fiber breakage ${ }^{40,41}$. For example, a mushroom head indicates that the fracture was caused by a high tensile force (Figure S11). For washing the most relevant scenario is breakage by fatigue failure, resulting in fiber ends that have been split into finer fibers or fibrils ${ }^{41}$. Another form of fiber failure is surface wear and peeling, which often leads to tapered ends or multiple splits ${ }^{41}$. In our experiments, the SEM images showed no sign of fibrillation or splits at the fiber end. Most of the MPF released from scissor-cut samples during the $1^{\text {st }}$ and $10^{\text {th }}$ wash cycles showed a solid end similar to the scissor-cut ones. Some MPFs exhibited distorted ends seem to be originated during manufacturing process where mechanical stress such as transverse pressure can happen deliberately or accidentally.

The relatively steady release of MPF after a few washings suggests that a part of the fibers have a slow release dynamics. The MPF released during the $10^{\text {th }}$ wash cycle were significantly longer compared to the MPF from the $1^{\text {st }}$ wash cycle for most of the samples. Since longer fibers are more entangled within 
the textile structure, they may require more time to work their way out from textile. It may be possible that additional breakage and release of fibers could be expected during laundering with older textiles as they experience more wear during use, but this was not evaluated in this present study.

The textiles with mechanically processed surfaces exhibited higher MPF releases than those with untreated surfaces, which was also observed in some other studies ${ }^{21,30}$. Processed surfaces investigated by this study are produced by cutting surface fibers by blade or brush. On one hand, it is possible that a number of loosely entangled MPF are generated during this process. On the other hand, such processes can loosen both yarn and surface structure, therefore making the release of MPF from within the textile structure easier. The statistical analysis showed that the MPF released from the laser-cut processed textiles had shorter lengths suggesting that shorter MPF may be generated during the surface treatment process. Another point worth noting is that although textiles with processed surface sheds higher amount of MPFs at the beginning, after ten rounds of washing, the MPF release decreased to the same level than the unprocessed textiles.

We hypothesized that higher mechanical stress will lead to higher MPF release during washing, since the steel balls may contribute to the abrasive friction on the fibers or to increase textile bending and consequently loosening the structure to release more pre-existing MPF. However, the mechanical stress enacted by adding different number of steel balls did not influence the number and length of MPF released for most samples in our experiment. This may be due to the timeframe of the experiment was too short to observe any significant impact induced by adding steel balls.

Two aspects are suspected to contribute to the fact that the scissor-cut samples released more MPFs than the laser-cut textiles. On one hand, the cutting process may open up the yarn at the end which results in the release of MPF present inside. On the other hand, it is also possible that some new MPFs are generated during the cutting processes. This can be derived from the fact that some scissor-cut samples released significant longer MPFs than the laser-cut ones, which is an indication that a new population of MPFs may be formed. For the laser-cut samples, the yarns are melted together at the end which largely prevent the "opening up" at the yarn end. Moreover, even though the laser cutting can generate some new MPF similar to scissor cutting, most of those newly generated MPFs will be probably melted/bonded into "solid" ends. Therefore, most of them cannot be released in the future washing process.

Most of the cutting/sewing methods (model cutting, double sewing and overlock sewing) did not significantly reduce the MPF release from textile during washing, which is against our hypothesis that textile with sewn edge release less MPF. The overlock-sewn sample even released higher numbers of MPF than the samples with raw edges. The elevated level of release may be due to additional damage by cutting or needling during the overlock sewing process. Since overlock sewing is one of the most commonly used hemming/seaming methods in the textile industry, this finding is highly relevant for 
those who want to identify the stages responsible for the generation of MPF during the textile manufacturing.

The evaluation of the results using the different cutting/sewing method can be used to gain additional insight on the origin of MPF released from within the textile. The SEM images show that the edges of laser-cut samples were molten and sealed, while the scissor-cut edges were loose and open (Table S2). Therefore, we can assume that all the MPF released from laser-cut samples originate from the textile surface rather than the edges. For the scissor-cut textiles it can then be expected that release from the textile surface should be equal to the laser-cut samples and that the additional fibers measured are released from the edges. Therefore, a "release equation" can be proposed for each textile (Equation 1):

$$
\text { Release }_{\text {textile }}=\underbrace{\frac{M P F_{L C}}{\text { area }_{\text {sample }} * \text { mass }_{\text {sample }}}}_{\text {Release }_{\text {surface }}} * \text { area }_{\text {textile }}+\underbrace{\frac{M P F_{S C}-M P F_{L C}}{\text { perimeter }_{\text {sample }} * \text { mass }_{\text {sample }}}}_{\text {Release }_{\text {edge }}} * \text { perimeter }_{\text {textile }}
$$

Equation

where "MPF $\mathrm{SC}_{\mathrm{SC}}$ and "MPF $\mathrm{LC}_{\mathrm{LC}}$ are the MPF releases from the scissor- and laser-cut samples respectively,

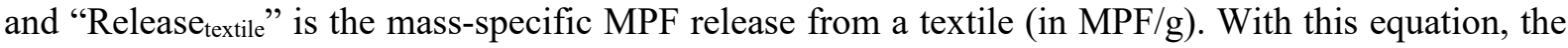
number of MPF released from a larger piece of textile can be predicted as shown in Table 2. For 10 out of 12 textiles, the MPFs shedding from edges contributed to more than $80 \%$ to the total release. It is worth noting that the majority of MPF released from textiles with processed surface still originated from the cut edge, especially for Plain B where the edge was responsible for more than $90 \%$ of the MPF release. For the edge-to-surface ratio, no statistically significant influence was found by the surface treatment, the textile structure and the yarn type.

Table 2. Estimated mass-specific MPFs released per $\mathrm{cm}^{2}$ surface area and per $\mathrm{cm}$ perimeter from the textile samples $\left(4 \times 10 \mathrm{~cm}^{2}\right)$ during washing when fabric swatches have a scissor-cut edge. Release from the fabric surface is measured from fabric swatches with laser-cut edges. The ratio of the MPF release from the edges and surface was calculated for the sample that has an area of $40 \mathrm{~cm}^{2}$ and a perimeter of $28 \mathrm{~cm}$. Release surface $_{\text {and }}$ Release $e_{\text {edge }}$ were calculated based on Equation (1).

\begin{tabular}{cccc}
\hline Textile & $\begin{array}{c}\text { Release } \\
{\left[\mathrm{MPF} /\left(\mathrm{cm}_{\text {edge }} * \mathrm{~g}\right)\right.}\end{array}$ & $\begin{array}{c}\text { Release }_{\text {surface }} \\
{\left[\mathrm{MPF} /\left(\mathrm{cm}^{2 *} \mathrm{~g}\right)\right]}\end{array}$ & $\begin{array}{c}\text { Release }_{\text {edge }} / \text { Release }_{\text {surface }} \\
{[\mathrm{cm}]}\end{array}$ \\
\hline Satin F & 26 & 19 & 1 \\
Twill F & 100 & 5 & 19 \\
Rib F & 193 & 7 & 30 \\
Plain F & 186 & 19 & 10 \\
Terry S & 221 & 9 & 23 \\
Plain S & 235 & 28 & 9 \\
Rib S & 249 & 31 & 8 \\
Jersey S & 291 & 23 & 12 \\
Interlock S & 391 & 15 & 26 \\
Fleece & 475 & 253 & 2 \\
Plain B & 1251 & 58 & 22 \\
Microfiber & 2001 & 408 & 5 \\
\hline
\end{tabular}


The 12 textiles investigated in our work demonstrated a great variability in MPF release. The upper limit observed in our study is much higher than found in other studies reporting a range from 4 to $13^{\prime} 000$ MPF (Figure S12). The length range of the fibers released in our study $(100-1000 \mu \mathrm{m})$ is in accordance with previous measurements ${ }^{22,24,27,29}$. The MPF release from the Microfiber (72’000 MPF/g), is the highest among all the published studies in terms of fiber number. The generally higher number of MPF released in our study can be explained by the higher edge-to-surface ratio $(0.70 \mathrm{~cm})$ of our samples compared to other Gyrowash studies (with a ratio of $0.34-0.43 \mathrm{~cm})^{21,22,25}$. Since we have found that the edge released much more MPFs than the surface of textile, the higher edge-to-surface ratio will result in higher MPF release when the result is normalized to the textile weight. Some previous studies reported lower release in terms of number but higher mass release per wash compared to our study (Table S12, Figure S12 and S13). That may because a few studies only measured the weight of the released MPFs and estimated the fiber number based on the average length of a few MPFs. The mean value is influenced by extremes which may not be accurate enough. Therefore, we believe it is conceptually better to work with a number-based MPF release method.

Since our study has shown that the majority of the released MPFs during washing likely originate from edges instead of the surface of the textile, adopting the cleaner cutting technique is important for industry to help reduce the MPF release from textile as a source of microplastics. Furthermore, a prewash of tailored garments at the factory could effectively collect a large portion of the production-inherited MPF. One thing to be kept in mind is that the MPF release quantified here were only those released during the laundering process. That may not accurately reflect a real world scenario, since other processes such as wearing process are also involved and may account for additional MPF releases in subsequent washes as the textile ages. In addition, when standardizing the quantification method of MPF release from textiles, it is extremely important to be cautious about the cutting methods and edge-surface ratio. Besides, although the image analysis method is time consuming, it is conceptually better than the massbased method if we want to gain a complete profile of the MPF release (number, length).

\section{Acknowledgements}

We would like to thank Melanie Halter from Empa for the assistance in the preparation of textile samples. This research was partially supported by funds from the Zürcher Stiftung für Textilforschung. 


\section{Supporting Information}

SEM images for 12 textiles, examples of cutting/sewing methods, SEM images for edges, discussion and assessment of the washing procedure, number of MPF released during $1^{\text {st }}$ wash cycle, length of MPF released during the $1^{\text {st }}$ wash cycle, number of MPF released during repeated wash cycles, median length of the released MPF during $1^{\text {st }}$ and $10^{\text {th }}$ wash cycles, estimated cumulative release during 10 wash cycles, influence of mechanical stress on number and length of MPF released from textile, number and length of MPF released with different cutting/sewing methods, comparison of MPF release between washing and ultrasonication, comparison of the results from different washing studies.

\section{References}

1. Desforges, J.-P. W.; Galbraith, M.; Dangerfield, N.; Ross, P. S., Widespread distribution of microplastics in subsurface seawater in the NE Pacific Ocean. Marine Pollution Bulletin 2014, 79, (12), 94-99.

2. Woodall, L. C.; Sanchez-Vidal, A.; Canals, M.; Paterson, G. L.; Coppock, R.; Sleight, V.; Calafat, A.; Rogers, A. D.; Narayanaswamy, B. E.; Thompson, R. C., The deep sea is a major sink for microplastic debris. Royal Society Open Science 2014, 1, (4), 140317.

3. Kaya, A. T.; Yurtsever, M.; Bayraktar, S. C., Ubiquitous exposure to microfiber pollution in the air. European Physical Journal Plus 2018, 133, (11).

4. Ng, K.; Obbard, J., Prevalence of microplastics in Singapore's coastal marine environment. Marine Pollution Bulletin 2006, 52, (7), 761-767.

5. Zarfl, C.; Matthies, M., Are marine plastic particles transport vectors for organic pollutants to the Arctic? Marine Pollution Bulletin 2010, 60, (10), 1810-1814.

6. Rillig, M. C., Microplastic in terrestrial ecosystems and the soil? . Environmental Science \& Technology 2012, 46, (12), 6453-6454.

7. Van Cauwenberghe, L.; Claessens, M.; Vandegehuchte, M. B.; Janssen, C. R., Microplastics are taken up by mussels (Mytilus edulis) and lugworms (Arenicola marina) living in natural habitats. Environmental Pollution 2015, 199, 10-17.

8. Nelms, S. E.; Galloway, T. S.; Godley, B. J.; Jarvis, D. S.; Lindeque, P. K., Investigating microplastic trophic transfer in marine top predators. Environmental Pollution 2018, 238, 999-1007. 9. Anderson, P. J.; Warrack, S.; Langen, V.; Challis, J. K.; Hanson, M. L.; Rennie, M. D., Microplastic contamination in Lake Winnipeg, Canada. Environ Pollution 2017, 225, 223-231. 10. Su, L.; Xue, Y. G.; Li, L. Y.; Yang, D. Q.; Kolandhasamy, P.; Li, D. J.; Shi, H. H., Microplastics in Taihu Lake, China. Environmental Pollution 2016, 216, 711-719. 
11. Baldwin, A. K.; Corsi, S. R.; Mason, S. A., Plastic Debris in 29 Great Lakes Tributaries: Relations to Watershed Attributes and Hydrology. Environmental Science \& Technology 2016, 50, (19), 10377-10385.

12. Kawecki, D.; Nowack, B., Polymer-Specific Modeling of the Environmental Emissions of Seven Commodity Plastics As Macro- and Microplastics. Environmental Science \& Technology 2019, $53,(16), 9664-9676$.

13. Henry, B.; Laitala, K.; Klepp, I. G., Microfibres from apparel and home textiles: Prospects for including microplastics in environmental sustainability assessment. Science of the Total Environment 2019, 652, 483-494.

14. Browne, M. A.; Crump, P.; Niven, S. J.; Teuten, E.; Tonkin, A.; Galloway, T.; Thompson, R., Accumulation of microplastic on shorelines woldwide: sources and sinks. Environmental Science \& Technology 2011, 45, (21), 9175-9179.

15. Sun, J.; Dai, X.; Wang, Q.; van Loosdrecht, M. C.; Ni, B.-J., Microplastics in wastewater treatment plants: Detection, occurrence and removal. Water Research 2019, 152, 21-37.

16. Schmiedgruber, M.; Hufenus, R.; Mitrano, D. M., Mechanistic understanding of microplastic fiber fate and sampling strategies: Synthesis and utility of metal doped polyester fibers. Water Research 2019, 155, 423-430.

17. Keller, A. S.; Jimenez-Martinez, J.; Mitrano, D. M., Transport of nano-and microplastic through unsaturated porous media from sewage sludge application. Environmental Science \& Technology 2020, 54, (2), 911-920.

18. Nizzetto, L.; Futter, M.; Langaas, S., Are agricultural soils dumps for microplastics of urban origin? Environmental Science \& Technology 2016, 50, (20), 10777.

19. Corradini, F.; Meza, P.; Eguiluz, R.; Casado, F.; Huerta-Lwanga, E.; Geissen, V., Evidence of microplastic accumulation in agricultural soils from sewage sludge disposal. Science of the Total Environment 2019, 671, 411-420.

20. Zubris, K. A. V.; Richards, B. K., Synthetic fibers as an indicator of land application of sludge. Environmental Pollution 2005, 138, (2), 201-211.

21. Almroth, B. M. C.; Åström, L.; Roslund, S.; Petersson, H.; Johansson, M.; Persson, N.-K., Quantifying shedding of synthetic fibers from textiles; a source of microplastics released into the environment. Environmental Science and Pollution Research 2018, 25, (2), 1191-1199.

22. De Falco, F.; Gullo, M. P.; Gentile, G.; Di Pace, E.; Cocca, M.; Gelabert, L.; Brouta-Agnesa, M.; Rovira, A.; Escudero, R.; Villalba, R.; Mossotti, R.; Montarsolo, A.; Gavignano, S.; Tonin, C.; Avella, M., Evaluation of microplastic release caused by textile washing processes of synthetic fabrics. Environmental Pollution 2018, 236, 916-925.

23. Hartline, N. L.; Bruce, N. J.; Karba, S. N.; Ruff, E. O.; Sonar, S. U.; Holden, P. A., Microfiber Masses Recovered from Conventional Machine Washing of New or Aged Garments. Environmental Science \& Technology 2016, 50, (21), 11532-11538. 
24. Hernandez, E.; Nowack, B.; Mitrano, D. M., Polyester Textiles as a Source of Microplastics from Households: A Mechanistic Study to Understand Microfiber Release During Washing.

Environmental Science \& Technology 2017, 51, (12), 7036-7046.

25. Jonsson, C.; Arturin, O. L.; Hanning, A. C.; Landin, R.; Holmstrom, E.; Roos, S., Microplastics Shedding from Textiles-Developing Analytical Method for Measurement of Shed Material Representing Release during Domestic Washing. Sustainability 2018, 10, (7).

26. McIlwraith, H. K.; Lin, J.; Erdle, L. M.; Mallos, N.; Diamond, M. L.; Rochman, C. M., Capturing microfibers-marketed technologies reduce microfiber emissions from washing machines. Marine Pollution Bulletin 2019, 139, 40-45.

27. Napper, I. E.; Thompson, R. C., Release of synthetic microplastic plastic fibres from domestic washing machines: Effects of fabric type and washing conditions. Marine Pollution Bulletin 2016, $112,(1-2), 39-45$.

28. Pirc, U.; Vidmar, M.; Mozer, A.; Krzan, A., Emissions of microplastic fibers from microfiber fleece during domestic washing. Environmental Science and Pollution Research 2016, 23, (21), 22206-22211.

29. Sillanpaa, M.; Sainio, P., Release of polyester and cotton fibers from textiles in machine washings. Environmental Science and Pollution Research 2017, 24, (23), 19313-19321.

30. Belzagui, F.; Crespi, M.; Álvarez, A.; Gutiérrez-Bouzán, C.; Vilaseca, M., Microplastics' emissions: Microfibers' detachment from textile garments. Environmental Pollution 2019, 248, 10281035.

31. De Falco, F.; Di Pace, E.; Cocca, M.; Avella, M., The contribution of washing processes of synthetic clothes to microplastic pollution. Scientific Reports 2019, 9, (1), 6633.

32. Kelly, M. R.; Lant, N. J.; Kurr, M.; Burgess, J. G., Importance of Water-Volume on the Release of Microplastic Fibers from Laundry. Environmental Science \& Technology 2019, 53, (20), 11735-11744.

33. De Falco, F.; Gentile, G.; Di Pace, E.; Avella, M.; Cocca, M., Quantification of microfibres released during washing of synthetic clothes in real conditions and at lab scale $\star$. The European Physical Journal Plus 2018, 133, (7), 257.

34. Gries, T.; Veit, D.; Wulfhorst, B., Textile technology: an introduction. Carl Hanser Verlag GmbH Co KG: 2015.

35. Choudhury, A. K. R., Principles of textile finishing. Woodhead Publishing: 2017.

36. ISO, 105-C06:2010: Textiles-Tests for Colour Fastness Part C06: Colour Fastness to Domestic and Commercial Laundering. 2010.

37. Usov, I.; Mezzenga, R., FiberApp: an open-source software for tracking and analyzing polymers, filaments, biomacromolecules, and fibrous objects. Macromolecules 2015, 48, (5), 12691280. 
38. Kallay, N.; Grancari, A.; Tomi, M., Kinetics of polyester fiber dissolution. Textile Research Journal 1990, 60, (11), 663-668.

39. Chambers, J. M.; Cleveland, W. S.; Kleiner, B.; Tukey, P. A., Graphical methods for data analysis. 1983. Wadsworth and Brooks/Cole.

40. Morton, W. E.; Hearle, J.W.S., Physical Properties of Textile Fibres (Fourth edition). Woodhead Publishing Series in Textiles 2008, 509-558.

41. Hearle, J. W.; Lomas, B.; Cooke, W. D., Atlas of fibre fracture and damage to textiles. Elsevier: 1998. 